\title{
Ecology, Cognition, and the Hippocampus: A Tale of Two Frogs
}

\author{
Sabrina S. Burmeister \\ Department of Biology, University of North Carolina, Chapel Hill, NC, USA
}

\section{Keywords}

Cognition - Spatial memory - Behavioral flexibility .

Medial pallium · Hippocampus · Amphibian · Poison frog ·

Dendrobates auratus · Túngara frog

\begin{abstract}
The underlying hypothesis that motivates research into the relationship between ecology, cognition, and the hippocampus is that selection to solve problems in nature shapes cognition through changes in the hippocampus. This hypothesis has been explored almost exclusively in mammals and birds. However, if one is interested in the principles that shape the evolution of vertebrate cognition, work in amphibians is essential. To address this gap, we have developed a research program contrasting cognitive abilities and hippocampal neurobiology in two species of frog with distinct social and spatial ecologies. We have found that the poison frog Dendrobates auratus, a diurnal species whose interactions with the physical and social environment are complex, is more adept and flexible at spatial learning and learned inhibition than the túngara frog, a nocturnal species that lacks complex interactions with the spatial and social environment. Because spatial learning and learned inhibition are
\end{abstract}

closely associated with hippocampal function in other vertebrates, we used RNA sequencing to characterize molecular differences in the hippocampus of the two species. We have found that $D$. auratus has greater levels of expression of genes associated with neurogenesis, synaptic plasticity, and cellular activity, and lower levels of expression of genes associated with apoptosis, compared to the túngara frog. Our studies are consistent with the idea that $D$. auratus, with their more complex social and spatial ecology, have enhanced hippocampally dependent cognitive abilities compared to túngara frogs. Further characterization of the features of hippocampal neurobiology that confer distinctive cognitive abilities will help elucidate the neural features that are necessary for the evolution of enhanced hippocampally dependent cognition.

(c) 2022 S. Karger AG, Basel

\section{Preface}

Walter Wilczynski (1952-2020) was an exceptionally broad thinker. With training as a comparative neurobiologist, his inherent curiosity and open mind created a lab community with people working on a variety of dif- 
ferent species and questions. I was fortunate enough to be a member of Walt's lab as a graduate student where I began my career studying the neurobiology of communication in the context of sexual selection. My lab colleagues introduced me to topics as diverse as dopamine receptor pharmacology [Chu et al., 2001], neuroendocrinology of social behavior of lizards [Yang and Wilczynski, 2002], and the relationships among ecology, cognition, and the hippocampus [Day et al., 1999a; Bilbo et al., 2000]. Each of these topics influenced the trajectory of my research and several eventually intersected with my research on the neurobiology of communication [e.g., Burmeister et al., 2017, 2020]. My introduction to the relationship between ecology and hippocampally dependent cognition in Walt's lab set the stage for a later bifurcation of my own research program which now encompasses both the neurobiology of communication and comparative cognition, directly leading to the work I will describe here.

\section{Introduction}

The relationship between ecology and hippocampally dependent cognition is a topic of long-standing interest [Shettleworth and Hampton, 1998] and is based primarily on our understanding of hippocampal function in mice and rats. The dogma, as it were, is that the mammalian hippocampus is specialized for learning about spatial relationships. For example, in the classic study by Morris et al. [1982], hippocampal lesions disrupted the ability of rats to use an array of distal cues to find a hidden platform, but animals were still capable of using direct guidance to a proximal cue/beacon. However, the hippocampus is associated with other aspects of cognition, including the ability to inhibit learned responses [Chan et al., 2001; Sakimoto and Sakata, 2014], which contributes to the capacity to behave flexibly in response to changes in the environment. Complex social and physical environments are associated with greater levels of behavioral flexibility [Bond et al., 2007; Amici et al., 2008], and spatial learning ability and navigational strategy are correlated with the types of spatial problems species must solve in nature [Brodbeck, 1994; Clayton and Krebs, 1994; MacDonald, 1997; Lavenex et al., 1998; Day et al., 1999a; Pravosudov and Clayton, 2002]. Thus, learned inhibition and spatial learning are both associated with ecology and natural history such that species whose ecology demands more complex interactions with the physical and social environment - for example, re- membering more locations or more individuals simultaneously - are more adept at spatial learning and are more flexible.

At the time I worked in Walt's lab, Staci Bilbo, Lainy Day, and Walt conducted a study on the performance of the Northern leopard frog in an analog of the Morris water maze [Bilbo et al., 2000]. They reported that the frogs could use a motor strategy (praxis) in combination with direct guidance toward a proximal cue (the visible platform) but were unable to choose the shortest route to the goal or to use an array of distal cues to find the hidden platform the way rodents do [Bilbo et al., 2000]. It was the only investigation of spatial learning in amphibians at the time - indeed, studies outside birds and mammals were just beginning to emerge [Day et al., 1999b; Holtzman et al., 1999; Lopez et al., 1999; Lopez et al., 2000] - and it raised the possibility that amphibians were incapable of learning about spatial relationships among distal cues to relocate a goal. Alternatively, as Bilbo et al. [2000] recognized, the potential interpretation that amphibians have poorly developed spatial learning abilities could simply reflect limitations of the particular study species, and they recommended testing species with specific ecological or behavioral adaptations to further understand this cognitive capacity in amphibians. About a decade later, a graduate student and I were inspired by the spectacular navigational feats of poison frogs to pursue this question anew.

Poison frogs (family Dendrobatidae) are primarily diurnal and occupy terrestrial habitats in neotropical rainforests. To accommodate terrestrial breeding, poison frog parents have evolved complex parental care [Vági et al., 2019], including clutch attendance which helps to prevent desiccation. Clutch attendance is thought to have promoted the evolution of territoriality [Pröhl, 2005], which is widespread among poison frog species. Once tadpoles hatch, parents must transport them to water sources where they can complete development. As tadpole deposition sites, some species use larger, stable bodies of water (e.g., streams) and others use smaller, ephemeral bodies of water that form in tree holes or phytotelmata (water filled cavities in terrestrial plants). Many poison frog species are toxic and display aposematic coloration [Summers and Clough, 2001], releasing them from predation pressures and promoting the use of phytotelmata as tadpole deposition sites [Carvajaal-Castro et al., 2021]. All three traits - tadpole transport, territoriality, and diurnality - may have contributed to the evolution of distinguishing cognitive abilities in this group. 
In addition to these complex interactions with their physical environment, many poison frogs engage in enduring social interactions beyond those with territorial neighbors. For example, Dendrobates auratus females display mate guarding and deceptive courtship [Summers, 2014] and Ranitomeya imitator are monogamous with ongoing care of the tadpoles that depends on interaction between the parents over the course of months [Brown et al., 2010]. The social interactions of the Northern leopard frog, in contrast, are transient, as they mate in lek-type mating aggregations during the breeding season and provide no parental care. Spatially, the behavior of Northern leopard frogs includes migration to natal ponds from overwintering sites and accurate homing following translocation, an ability that is apparently independent of visual cues [Dole, 1968]. While the cues and cognitive strategies that leopard frogs use when homing are unknown, they could include direct guidance toward a proximal cue or beacon (e.g., moving toward olfactory cues of pond), route learning (e.g., following a sequence of distal cues or landmarks), and/or path integration based on self-generated cues. However, they are not known to express behaviors that would require flexible memories for many locations. Taken together, we reasoned that the social and spatial ecology of poison frogs, in contrast with species such as the Northern leopard frog, suggest that hippocampally dependent cognition may be enhanced in this group.

To help put our studies of poison frog cognition into context, we decided to contrast the performance of green-and-black poison frogs (D. auratus) with that of túngara frogs using identical mazes and training protocols. Similar to Northern leopard frogs, túngara frogs (Engystomops $=$ Physalaemus pustulosus) are nocturnal and breed opportunistically in puddles, requiring only fleeting social interactions [Ryan, 1985]. Túngara frog parents make a foam nest but provide no ongoing parental care. Thus, while the two species are distributed in the same habitats and are similar in body size, túngara frogs do not exhibit the complex navigational feats, nor do they engage in the types of social interactions, for which poison frogs are known. Using a variety of mazes, cues, and tasks, we have contrasted the two species in spatial cognition, learned inhibition, and hippocampal neurobiology. Although a full picture is still emerging, our studies are consistent with the idea that $D$. auratus, with their more complex social and spatial ecology, have enhanced hippocampally dependent cognition compared to túngara frogs.

Ecology, Cognition, and the

Hippocampus: A Tale of Two Frogs

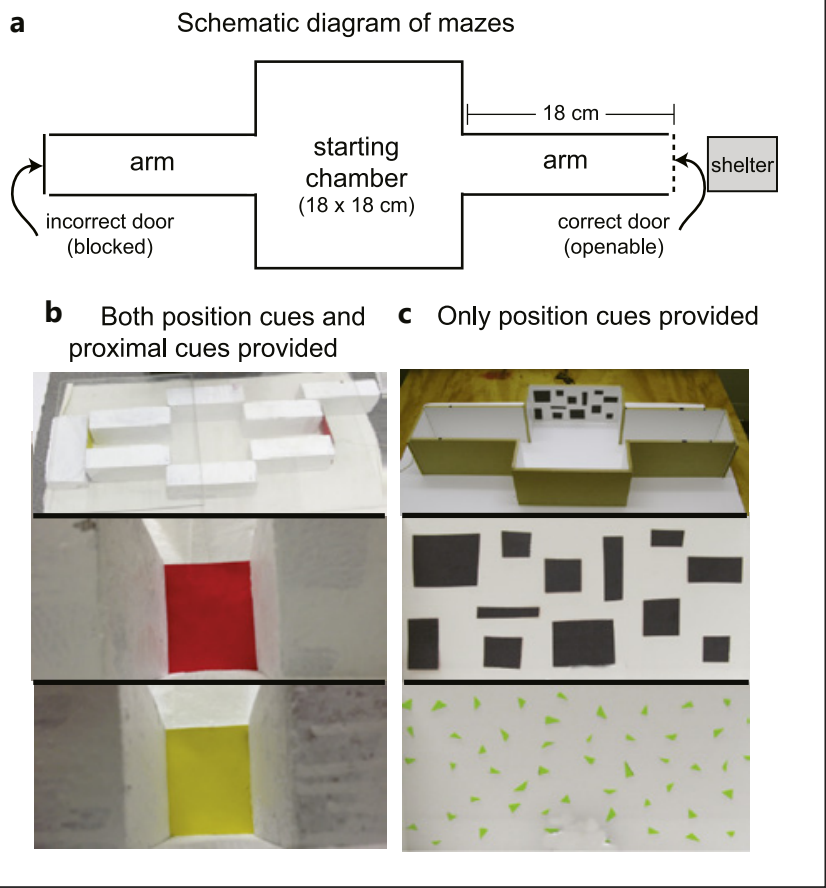

Fig. 1. Mazes and cues used to test spatial discrimination and reversal learning. In the task, frogs were released in a starting chamber and could choose one of two arms to locate an exit leading to a shelter and return to the home cage (a). In one iteration, the maze was constructed of painted bricks, and frogs could use position cues on the bricks and/or beacons (door color) to choose the correct exit (b). In a second iteration, the maze was constructed of uniform fiberboard and only position cues on the walls of the starting chamber were provided (c). Adapted with permission from Liu et al. [2020].

\section{Spatial Cognition}

The suite of processes that enable animals to acquire and use information about their physical environments can collectively be referred to as spatial cognition. For example, use of proximal cues/beacons enables an animal to use direct guidance (approach the cue to find the goal), a process thought to be a relatively simple association [Mackintosh, 2002]. In contrast, distal cues/landmarks can be used in a number of different ways including template matching (comparing the current view of the landscape with a remembered view), route learning (memorization of a series of landmarks), and the learning of spatial relationships (distances and directions) among an array of landmarks and goals [Shettleworth, 2009]. Learning the spatial relationships among an array of distal cues/ landmarks is thought to be the basis for creating an objec- 


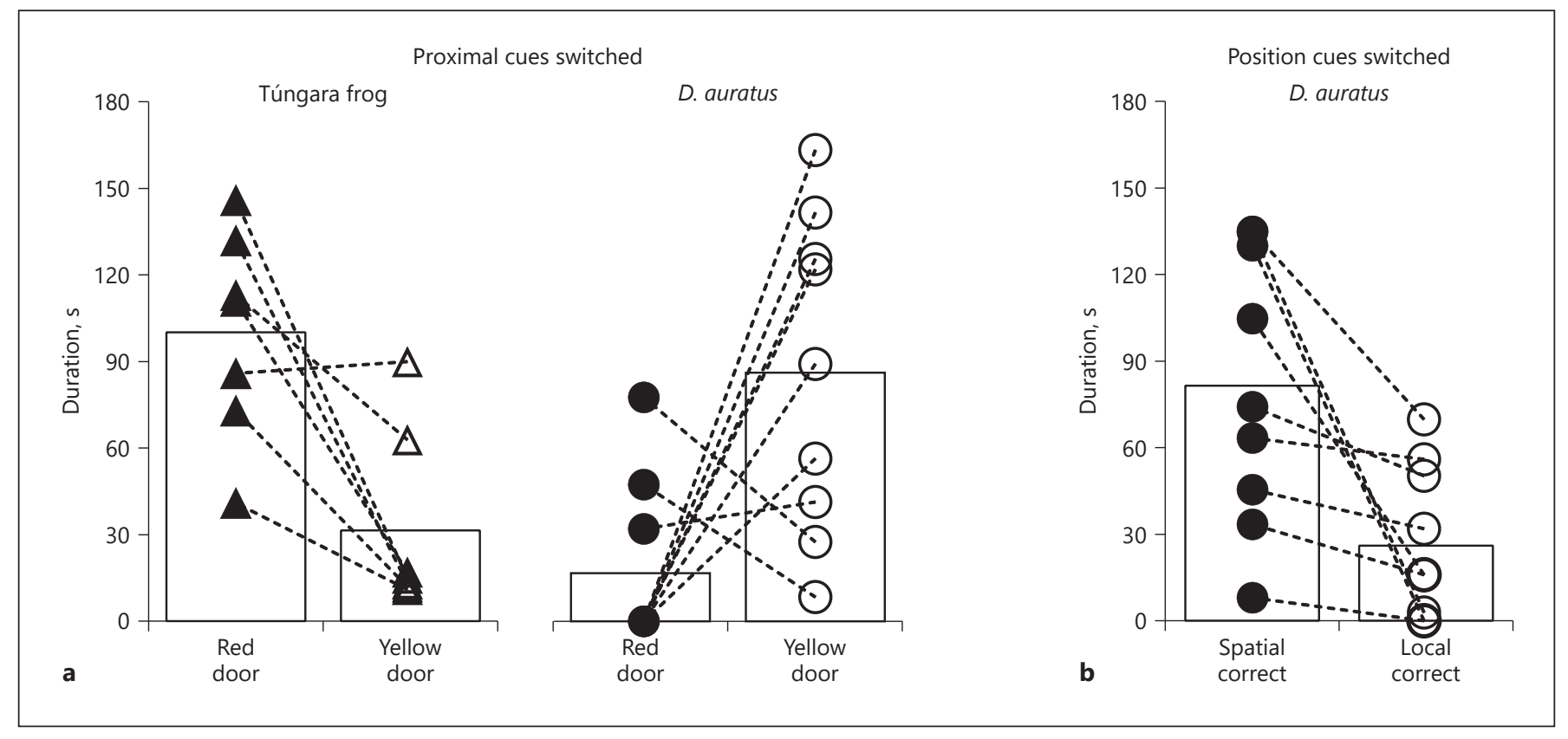

Fig. 2. While both species learned the two-choice spatial discrimination task, they used different cues to do so. When the proximal cue (door color) was switched, túngara frogs (indicated by triangles), but not D. auratus (indicated by circles), searched for the exit in the arm associated with the proximal cue (a). In contrast, when the position cues were switched, D. auratus searched for the exit in the arm that was spatially associated with the position cues (b). Individual performance is indicated by symbols connected by lines, and group means are indicated by bars. Adapted with permission from Liu et al. [2020].

tive representation of space that is independent of an animal's own position; the ability to form and use memories of spatial relationships is sometimes referred to as true spatial memory or a cognitive map [O'Keefe and Nadel, 1978; Mackintosh, 2002]. Because true spatial memory allows a highly flexible form of navigation that is best developed in species with spatial ecologies requiring flexible memories for many locations [Sherry et al., 1992], there has been great interest in understanding its evolution.

A key to successful comparative contrasts in cognition is to standardize the task on which species are to be compared. To do so, we have developed a simple discrimination task in which the animal chooses between two arms of a maze to locate a shelter. The correct arm of the maze can be indicated using a proximal cue that can be used as a beacon in direct guidance or by cues physically dissociated with the goal that we refer to as position cues (Fig. 1); the position cues in our two-arm maze are similar to distal cues in that they cannot be used in direct guidance. Frogs are motivated to locate the shelter in order to escape the bright, hot, and dry environment we create inside the maze. We find that both túngara frogs and $D$. auratus successfully learn to find the correct arm of the maze [Liu et al., 2020]. Using probe trials, however, we find consistent differences in the cues and strategies that the two species depend on when doing so: the túngara frogs readily learn to approach the proximal cue to locate the shelter while D. auratus prefer to use the position cues to orient within the maze (Fig. 2) [Liu et al., 2020]. In fact, when only position cues were provided, the túngara frogs still did not use them. This difference is reminiscent of differences between dark-eyed juncos (a non-storing species) and the food-storing black-capped chickadees where the chickadees depend more on spatial information than visual features of the remembered target to re-locate a goal [Brodbeck and Shettleworth, 1995].

Because our conclusions from the two-arm discrimination task are based on two different sets of visual cues, we believe that they are unlikely to stem from perceptual differences. However, given the species difference in diel activity, we need to consider the possibility that their differential performance can be attributed, at least in part, to differences in visual perception. To begin to address this issue, we tested the ability of the two species to use arena geometry to remember the location of a shelter in an open, hot environment. When using arrays of distal cues, 
Fig. 3. Poison frogs (D. auratus) are capable of using boundary geometry to learn the location of a goal. In a rectangular arena (a), D. auratus were trained to locate one of the two correct shelters. By day 15 of training, half the D. auratus reached the learning criterion of $77 \%$ (solid line), exceeding chance performance (dashed line; b). In probe trials in which the geometric cues were removed (c), performance fell back to $50 \%$ (dashed line; d), indicating that they had depended on boundary geometry during training. From Sorrell and Burmeister (unpubl.).

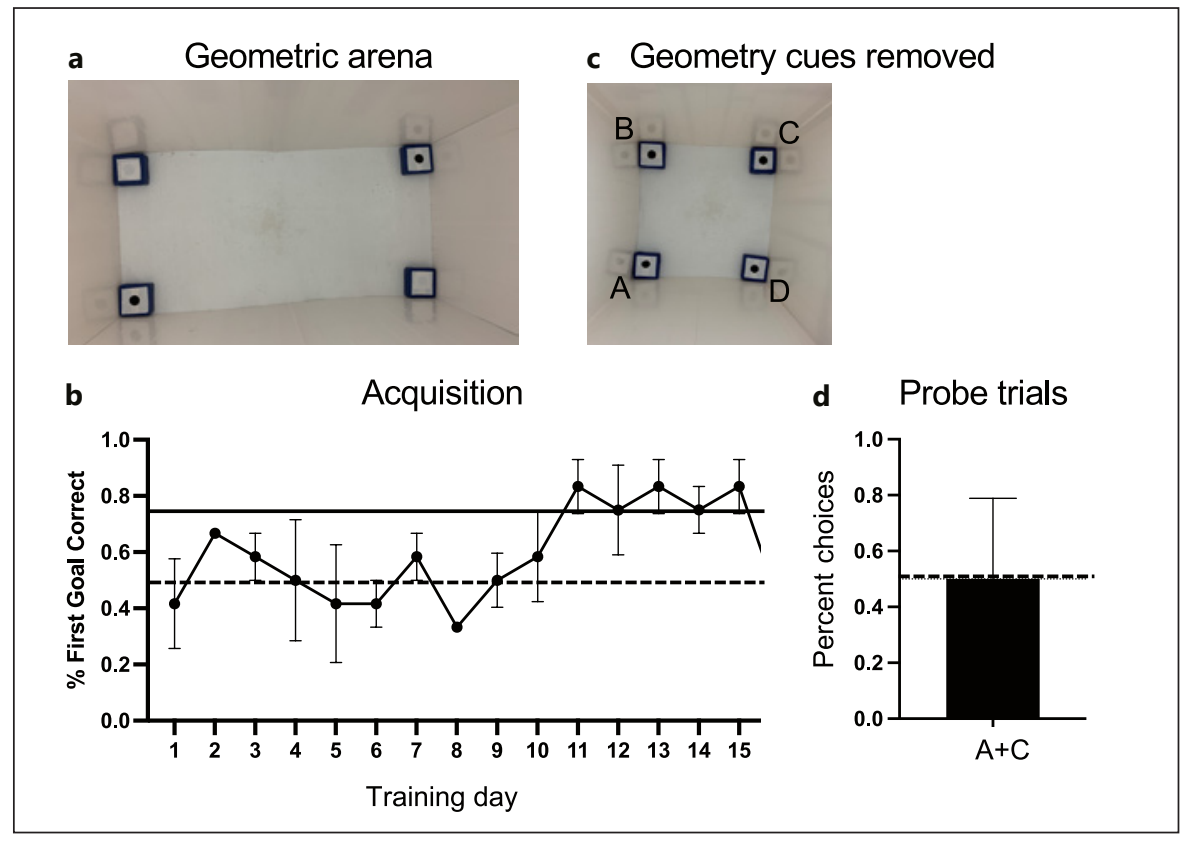

rats may utilize their geometric relationships to locate the goal [Cheng, 1986], and the ability to use boundary geometry to do so depends on the hippocampus [O'Keefe and Burgess, 1996; McGregor et al., 2004; Bingman et al., 2006; Bingman and Muzio, 2017]. In our geometric arena, the animals could find one of the two correct shelters by orienting correctly to the long and short arms of the arena (Fig. 3). Because there are no provided cues other than arena geometry, differential performance in this task should be independent of the salience of specific cues (e.g., contrast between red and yellow or size/shape of cues). In our preliminary results, we have found that 4 of 8 tested $D$. auratus are able to reach the learning criterion of 8 out of 9 correct first choices (Fig. 3), but only 1 of 8 túngara frogs succeeded. Probe trials confirmed that the $D$. auratus were using arena geometry to remember the location of the shelter (Fig. 3). These results give us increasing confidence in our conclusion that $D$. auratus are more adept at spatial learning than túngara frogs, which is consistent with our predictions from their spatial ecology.

The two-arm mazes and geometric arena can test the types of cues animals are using, but they do not allow us to test whether they are using an array of distal cues to choose the most efficient route to a goal. To test this element of spatial learning, we turned to the Morris water maze. The Morris water maze is one of the most prevalent mazes used in rodents, as it allows one to test the ability

Ecology, Cognition, and the

Hippocampus: A Tale of Two Frogs to take a direct route to a hidden goal based on an array of distal cues [Vorhees and Williams, 2006], and was instrumental in revealing the relationship between spatial learning and the hippocampus [Morris et al., 1982]. But the success of the Morris water maze depends on the exploration of the center of the maze where the hidden platform must be found. Many animals, including frogs [Bilbo et al., 2000] do not readily behave this way in a classic Morris water maze. Instead, they display strong thigmotaxis - swimming in circles as they touch the edge of the maze - rendering the classic Morris water maze unsuitable.

To overcome this challenge, we created a moat maze [Liu et al., 2019] based on the Morris water maze. Our moat maze capitalizes on the preference of $D$. auratus to walk rather than swim to reduce thigmotaxis: we submerged a circular table in the maze, leaving a deep moat near the edge. During pretraining, the frogs learned to avoid the moat and explore the table. The table was submerged enough below the surface that the platform, positioned in one quadrant of the table, was still hidden by the opaque water (Fig. 4) and the water was heated so that the frogs were motivated to find the platform. Under these conditions, we were able to test whether $D$. auratus could use an array of distal cues to take the most direct route to the goal. Using probe trials, we confirmed that the frogs depended on the provided array of cues to find the platform [Liu et al., 2019]. By analyzing the trajecto- 


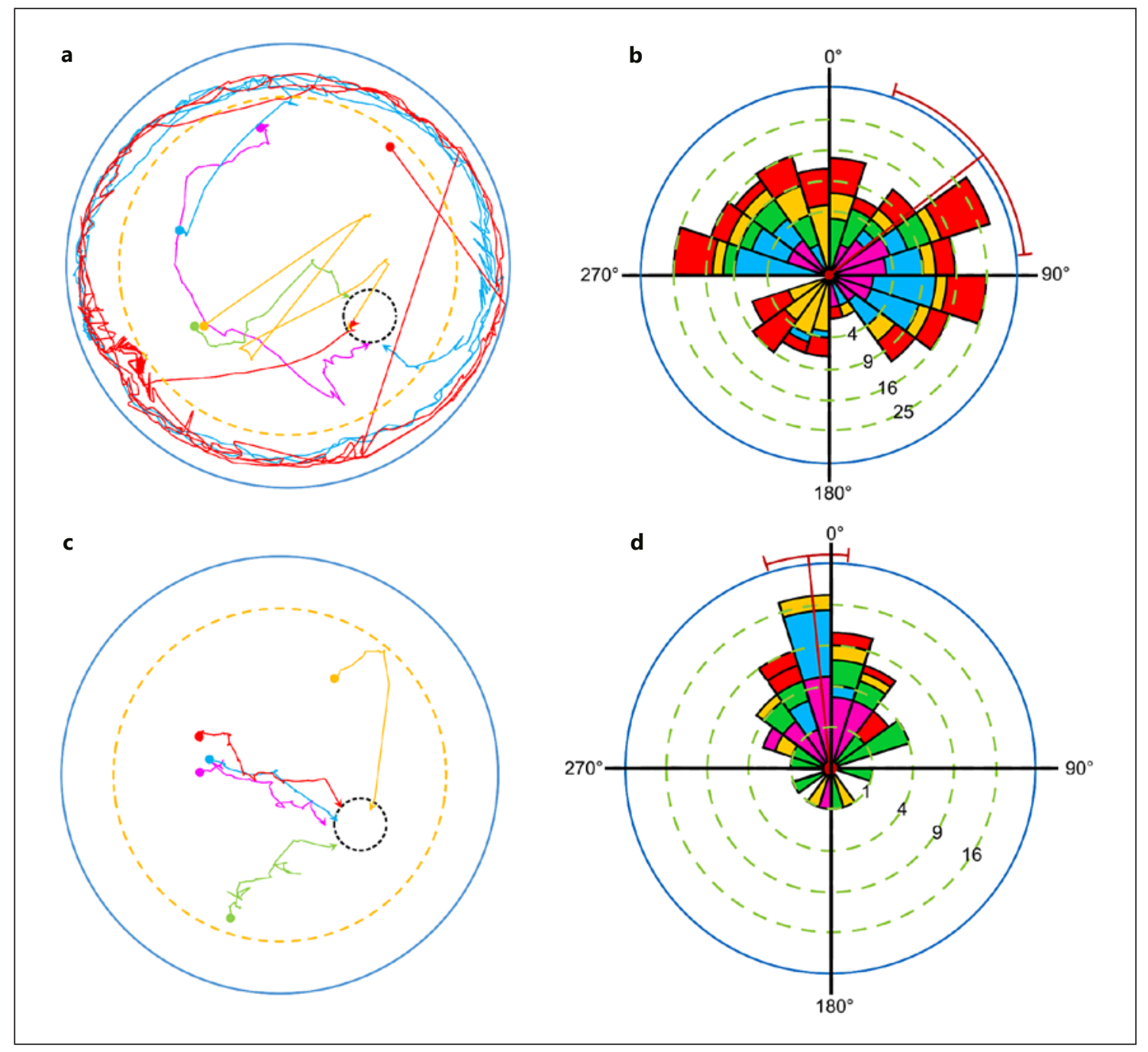

Fig. 4. In our moat maze, D. auratus learned to use an array of distal cues to take the most efficient route to the goal, regardless of release location. Early in training, the frogs showed thigmotaxis to the maze wall, taking indirect paths to the goal (a) that were not significantly oriented to the platform (b). After learning, the frogs were able to take direct paths toward the hidden platform (c) that were significantly oriented (d). In $\mathbf{a}$ and $\mathbf{c}$, the dashed yellow circle indicates the location of the table that creates a moat between the maze wall and the center of the arena; the dashed black circle indicates the location of the platform. Adapted with permission from Liu et al. [2019].

ries of individuals, we showed that, once they learned the task, they took direct paths to the platform regardless of release point (Fig. 4) [Liu et al., 2019], something Leopard frogs failed to do even when the platform was visible [Bilbo et al., 2000]. Unfortunately, this maze has proved unsuitable for túngara frogs, as their ability to float reduces the effectiveness of the moat in promoting the exploration of the center of the arena [J.-H. Yu and S.S. Burmeister, unpubl. data].
In summary, we find that túngara frogs prefer, and may depend on, proximal cues when remembering locations and have difficulty learning about spatial relationships. These findings comport well with túngara frog ecology, as in the nocturnal environment visual cues that are physically distant from a goal are likely of little use for orientation. In contrast, we find that $D$. auratus prefer position cues over proximal cues to find a goal, presumably by associating the direction from the cue to the goal, are capable of using arena geometry for navigation, and 
Fig. 5. Poison frogs (D. auratus; circles) are more adept at reversal learning in spatial discrimination tasks than túngara frogs (triangles). All D. auratus learned the reversal while none of the túngara frogs did (a). This difference in reversal learning was primarily due to a greater ability to inhibit learned responses, as shown by lower numbers of perseverative errors (the number of repeated approaches to the incorrect door after the initiation of reversal; b). Individual symbols represent individual animals; bars represent means with standard errors. Adapted with permission from Liu et al. [2020].

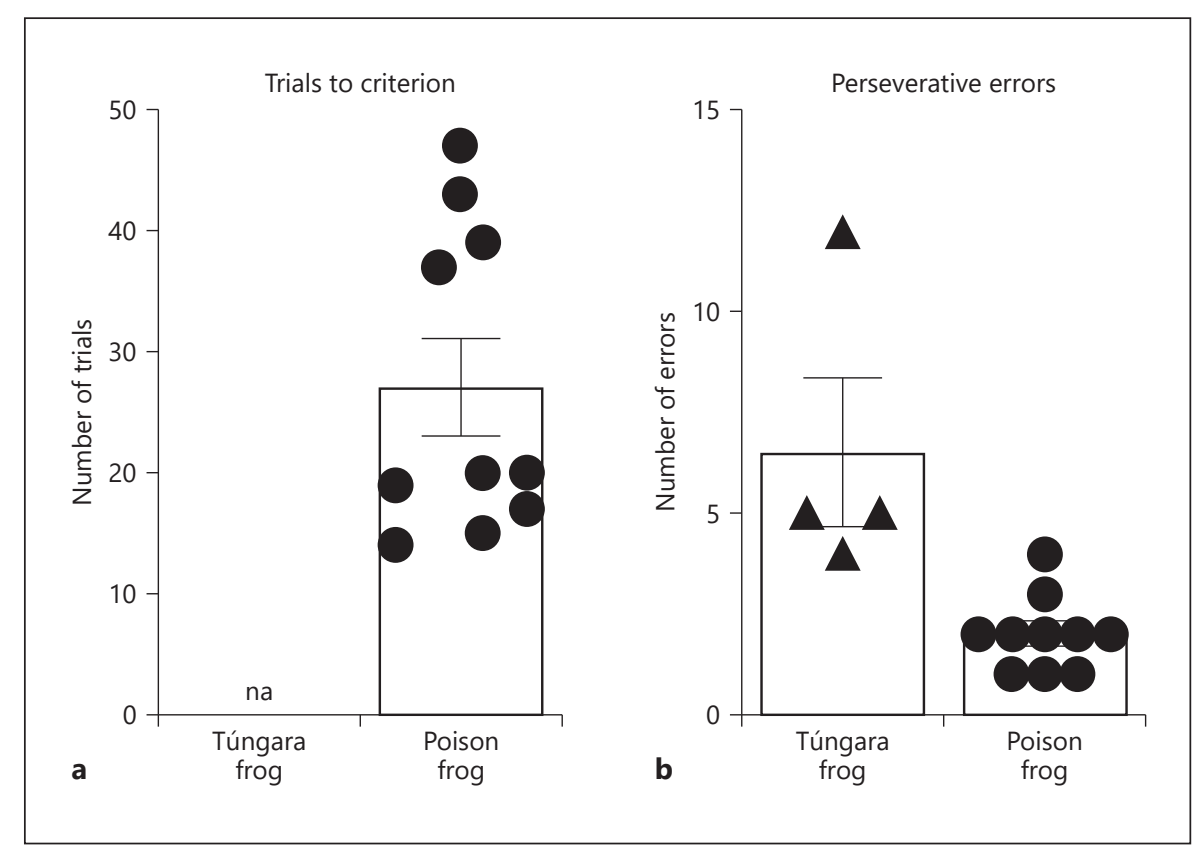

can use an array of distal cues to take direct paths to a goal. A preference for distributed visual cues makes sense for the diurnal poison frogs that must remember territorial boundaries and make use of spatially dispersed resources for parental care, as such cues allow for more flexible navigation. Taken together, our results provide the first example in amphibians of a relationship between spatial ecology and spatial cognition.

\section{Reversal Learning}

While the hippocampus is closely associated with the learning of spatial relationships, it also contributes to other aspects of cognition [Jarrard, 1995; Chan et al., 2001; Brasted et al., 2003; Banquet et al., 2021]. In fact, some have proposed that learned inhibition is a fundamental function of the hippocampus that ties together disparate aspects of hippocampally dependent cognition, including spatial learning, reversal learning, and context cue learning [Chan et al., 2001; Sakimoto and Sakata, 2014]. Similarly, others propose that an underlying function of the hippocampus is to represent reward contingency structure according to context, allowing an animal to adaptively respond to predicted changes in the environment [Vilà-Balló et al., 2017]. The ability to inhibit learned responses and behave adaptively allows animals to respond to complex physical and social environments in flexible ways and has been tied to ecological demands on social and spatial cognition [Godfrey-Smith, 2002; Dunbar and Shultz, 2007]. For example, compared to a sit-and-wait predator, lizards that actively forage for distributed prey items are more successful in reversal learning [Day et al., 1999b], a task that involves reversing reward contingencies once an initial discrimination is learned and that is dependent on learned inhibition.

If poison frogs and túngara frogs differ in hippocampally dependent cognition, therefore, they should also differ in their ability to inhibit previously learned responses. To test this prediction, we contrasted túngara frogs and $D$. auratus in reversal learning using our twoarm discrimination task, in which both species successfully acquired the initial discriminations. In both versions of the task, $D$. auratus, but not túngara frogs, learned the reversal [Liu et al., 2020]. An analysis of the types of errors committed during reversal showed that the túngara frogs committed significantly more perseverative errors than did D. auratus (Fig. 5) [Liu et al., 2020]. Perseverative errors are the number of repeated approaches to the incorrect door after the initiation of reversal and reflect how readily an animal can inhibit previously learned responses. Thus, we believe that a primary reason that túngara frogs are less adept at learning reversals than $D$. auratus is due to differences in learned inhibition. Interestingly, in some scenarios we find that female túngara frogs are more successful in learning the two-arm discrimination 


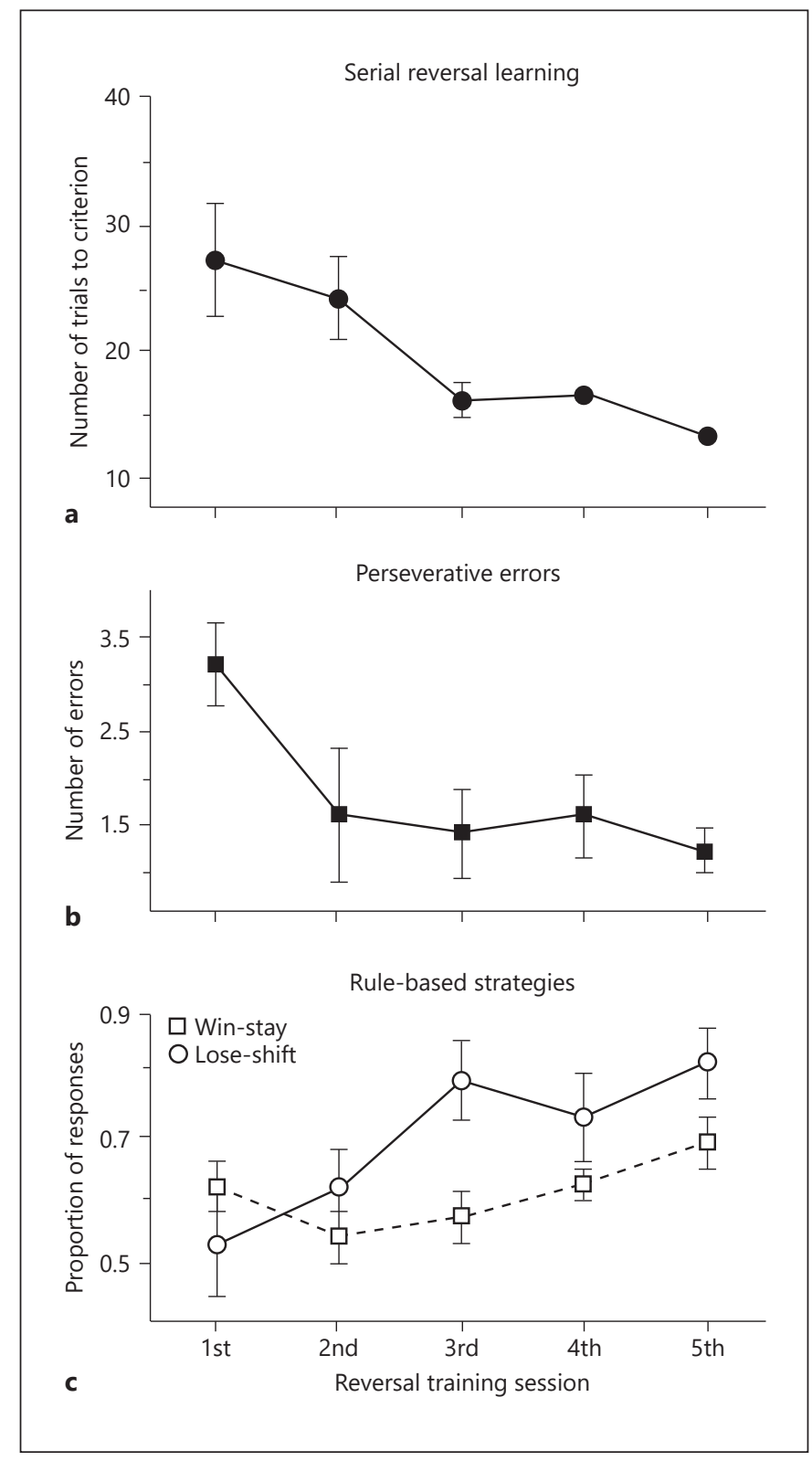

Fig. 6. In a serial reversal learning task, poison frogs (D. auratus) demonstrate an ability to learn the higher-order contingencies of the task. With each reversal, they learn the task more quickly, approaching perfect performance (a). Their improvement can be attributed, in part, to a reduction in the number of perseverative errors (the number of repeated approaches to the incorrect door after the initiation of reversal; b) which reflects the ability to inhibit previously learned responses. Finally, the increase in lose-shift responses (c) indicates an ability to use a rule-based strategy based on the higher-order contingencies of the task. Adapted with permission from Liu et al. [2016]. task than males due to sex differences in learned inhibition [Liu and Burmeister, 2017; Ventura et al., 2019]. Because the ability to reverse cannot be explained by differences in perceptual abilities (as both species learned the initial discrimination), this species difference in reversal learning lends confidence to our conclusion that túngara frogs and $D$. auratus differ in hippocampally dependent cognitive abilities. Broadly, our results are reminiscent of those found in corvids in which pinyon jays show greater behavioral flexibility during reversal learning compared to species with lower levels of social complexity [Bond et al., 2007].

In addition to assessing learned inhibition, the reversal learning task provides the opportunity to assess the ability to learn the higher-order structure of a task which reflects relationships among actions, rewards, and external variables. For example, in probabilistic reversal, the reversal of reward contingencies occurs after a variable number of trials, allowing animals to anticipate an upcoming reversal, an ability that is associated with hippocampal function [Vilà-Balló et al., 2017]. In serial reversal learning, reversals occur each time the animal reaches a predefined learning criterion and the underlying task structure dictates that, once a discrimination is learned, the contingencies reverse. If an animal is capable of higher-order contingency learning, we expect their performance to improve with each reversal (that is, they learn each reversal more quickly than the last), eventually, making only a single error on the first trial of a reversal before correcting their behavior. This is what D. auratus do in a serial reversal task in our two-arm maze (Fig. 6) [Liu et al., 2016]. Even more interesting, we find that they succeed because of a reduction in perseverative errors and an increased dependence on a lose-shift/win-stay strategy with each reversal (Fig. 6) [Liu et al., 2016], a strategy that reflects higher-order contingency learning. While a previous study had shown that the Eastern newt was able to improve performance across reversals [Ellins et al., 1982], $D$. auratus is the only amphibian in which it has it been established that they learned the higher-order structure of a reversal task. In fact, to our knowledge, this is still the only example of rule-based behavioral flexibility shown outside birds and mammals.

\section{Hippocampus}

The underlying hypothesis that motivates research into the relationship between ecology, cognition, and the hippocampus is that selection to solve problems in nature 
shapes cognition through changes in the hippocampus. Our behavioral contrast between two species of frog that differ in spatial and social ecology has revealed consistent differences in two aspects of cognition that, in other vertebrates, are specialized functions of the hippocampus. Before we turn to our studies contrasting the hippocampus of túngara frogs and $D$. auratus, it will be helpful to take a step back and consider what is known about the amphibian hippocampus and its function.

Based on developmental origin, hodology, and chemoarchitecture, the medial pallium is understood to be the amphibian homolog of the mammalian hippocampus proper (Ammon's horn, also known as CA1-4), although there is no clear homolog to the mammalian dentate gyrus, a structure that has been proposed to be a derivation within the mammalian lineage [Striedter, 2016; Bingman and Muzio, 2017]. One of the largest structures in the telencephalon, the medial pallium receives widespread input from sensory systems, pallial and subpallial structures including the nucleus accumbens, septum, and amygdala, and from the mesecephalic raphe nuclei [Butler and Hodos, 1996]. In turn, the medial pallium sends projections to both telencephalic and diencephalic targets, including sensory areas (anterior thalamus, olfactory bulb), septum, amygdala, ventral thalamus, preoptic area, and hypothalamus [Butler and Hodos, 1996]. There are at least two divisions - a ventral, small-celled population and a dorsal, large-celled population [Westhoff and Roth, 2002] - while some authors recognize a third division that is transitional between the medial and dorsal pallia [Westhoff and Roth, 2002]. The two primary divisions, in addition to differing in soma size, differ in hodology [Roth and Westhoff, 1999; Westhoff and Roth, 2002; Roth et al., 2007] and presumably function [e.g., Ewert et al., 2001].

While there is widespread agreement that the amphibian medial pallium is homologous to the amniote hippocampus, there are notable differences. For example, the amphibian medial pallium lacks the gross cytoarchitecture (i.e., layers or layer-like organization) and the double pyramidal cell morphology [cells of the medial pallium are uniformly pear-shaped; Roth and Westhoff, 1999] that characterize amniotes [Butler, 2017]. In addition, the amphibian medial pallium receives sensory input directly from the thalamus and olfactory bulb whereas, in amniotes, most sensory input is relayed through cortical areas. Finally, unlike the mammalian hippocampus, there are few interneurons in the medial pallium [Roth and Westhoff, 1999; Roth et al., 2007]. Functional studies of the amphibian medial pallium are relatively few, but they

Ecology, Cognition, and the

Hippocampus: A Tale of Two Frogs indicate that the medial pallium plays a broad role in associative learning [Muzio et al., 1993; Ewert et al., 2001; Puddington et al., 2016; Sotelo et al., 2016; Bingman and Muzio, 2017], including the learning of proximal cues and arena geometry [reviewed in Bingman and Muzio, 2017]. This contrasts with work in birds and mammals that show that the hippocampus contributes to the learning of spatial relationships and learned inhibition, but not typically to simpler types of associative learning, such as approach to a proximal cue [Jarrard, 1995; Chan et al., 2001]. Thus, the amphibian medial pallium appears less specialized than the hippocampus of amniotes in its function, and some have suggested that this broader functional repertoire of the anuran hippocampus may represent the ancestral state of the vertebrate hippocampus [Bingman and Muzio, 2017].

Studies examining the relationship between ecology, cognition, and the hippocampus have, almost without exception, assayed the hippocampus by measuring its relative volume [Healy, 2021] and several have found that hippocampal volume correlates with spatial learning ability across species [Healy and Krebs, 1992; Garamszegi and Marcel Eens, 2004]. Although more readily accessible than most physiological assays, measures of hippocampal volume can be problematic [Pravosudov and de Kort, 2006; LaDage et al., 2009; Gould et al., 2013]. Further, while the higher volume of the hippocampus in foodstoring birds has been attributed to a higher rate of neurogenesis in adults [Pravosudov and Smulders, 2010; Sherry and Hoshooley, 2010], hippocampal volume, and even neurogenesis, lack clear functional correlates. Because of this, we chose to use RNA sequencing to contrast the medial pallium of túngara frogs with that of $D$. auratus. We examined medial pallium RNA transcriptomes of naive frogs (without training) because our goal was to identify candidate functional pathways that contribute to species differences in cognitive capacity (i.e., the potential to learn). (Furthermore, because the two species have different learning abilities, it is not possible to compare them after learning the same association.) Using this approach, we found that neurogenesis-associated genes are more highly expressed, and apoptosis-associated genes are less highly expressed, in the medial pallium of $D$. auratus compared to the túngara frog (Fig. 7). Further, we found that differentially expressed genes associated with synaptic plasticity were upregulated in D. auratus (Fig. 7). Similar results have been found in chickadees where populations with better spatial learning ability express higher synaptic plasticity-related genes compared to populations with poorer spatial learning [Pravosudov et al., 


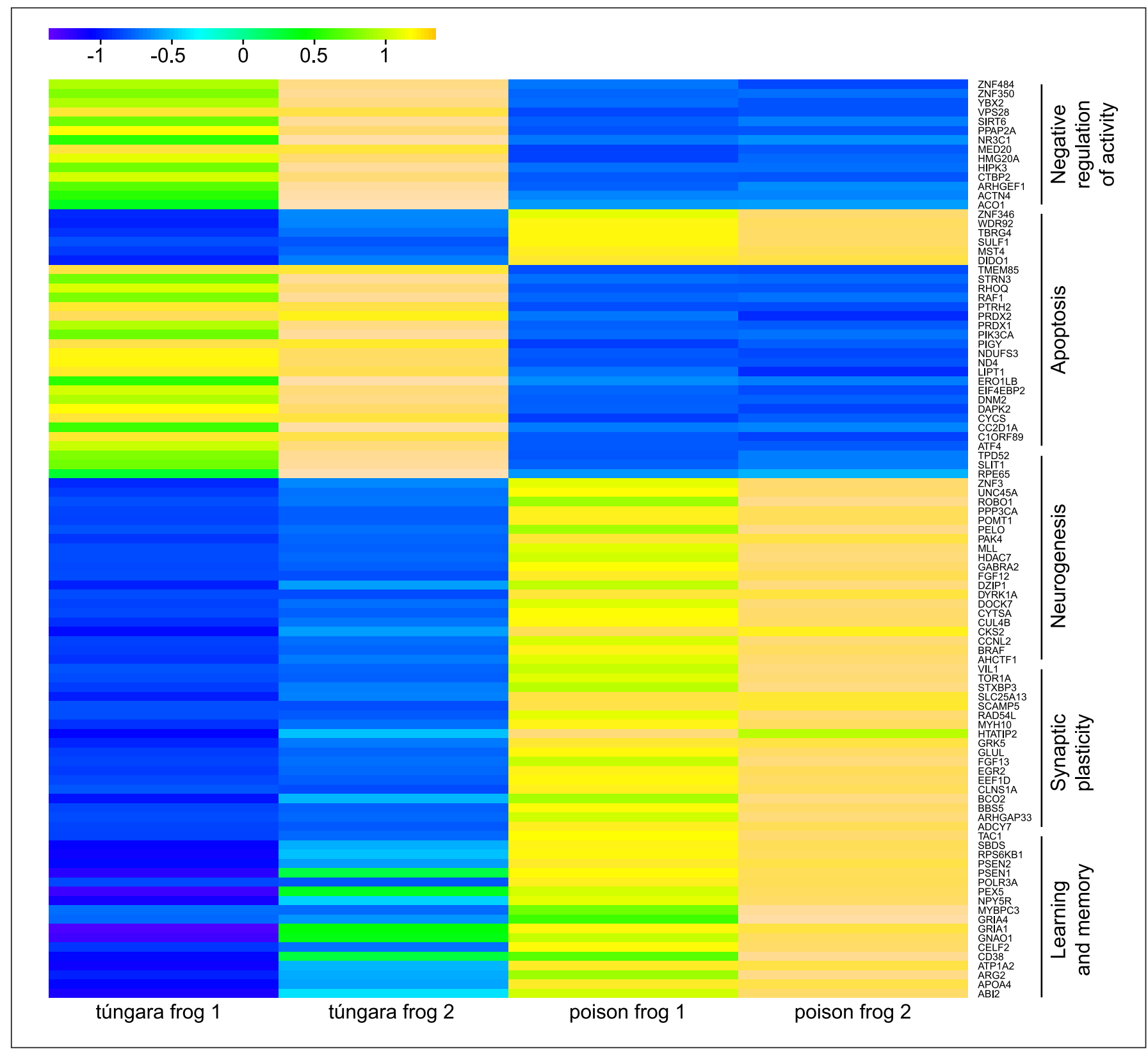

Fig. 7. Genes showing consistent patterns of differential expression in the medial pallium between túngara frogs and poison frogs (D. auratus), two species of frog that differ in cognitive abilities. Using GO terms to categorize genes, we found that among the transcripts with putative homologs to humans there is a strong enrichment for upregulated genes associated with learning and memory, synaptic plasticity, and neurogenesis and for downregulated genes associated with apoptosis and negative regulation of cellular activity. Reused with permission from Liu et al. [2020].

2013; Branch et al., 2021]. Finally, we found that genes that negatively regulate cellular activity were downregulated in D. auratus, indicating higher levels of protein synthesis, steroid synthesis, and cholesterol and fatty acid metabolism (Fig. 7). Because protein synthesis in the hip- pocampus is critical in long-term memory formation [Davis and Squire, 1984] and bilayer lipid membranes, cholesterol, and fatty acids are important material in neurogenesis [Koudinov and Koudinova, 2001; Das, 2003], our results indicate that the cognitive abilities evident in 
D. auratus may be associated with a higher level of hippocampal biosynthesis and metabolism.

The functional categories we assigned to differentially expressed genes were based on studies in mammals. To better characterize their role in medial pallium plasticity of $D$. auratus, we have conducted a preliminary study examining differential gene expression during a spatial discrimination task. We trained D. auratus in the twoarm maze using position cues [as in Liu et al., 2016] and collected samples from the medial pallium 1 day after they learned, matching trained frogs to naive controls. We assembled our transcriptome de novo, aligned transcripts to genes in the Xenopus genome, identified differentially expressed genes, and used GO enrichment analysis to examine putative functions. We found that 53 genes changed expression in response to training [Liu et al., unpubl.]. Similar to our findings in the species contrast, many of the genes that changed expressed in response to training were related to neurogenesis (e.g., BUB1B), anti-apoptotic (e.g., DHCR24), and cholesterol homeostasis (e.g., LDLR). These genes are closely associated with hippocampal function in mammals. For example, LDLR knockout impairs spatial learning [Wang et al., 2014] and neurogenesis [Engel et al., 2019]. Further, disruption of LDLR function is associated with mouse and human cell models of Alzheimer's disease [Abisambra et al., 2010], which is characterized by a decline in hippocampal function. Hippocampal downregulation of DHCR24 results in cognitive impairment in rats [Hosseinzadeh et al., 2015]. Insufficiency of BUB1B expression impaired hippocampal neurogenesis and leads to cognitive deficit in mice [Yang et al., 2017; Cho et al., 2018]. These data are broadly confirmatory that medial pallium plasticity in $D$. auratus is associated with similar cellular processes as in the mammalian hippocampus, although much more work needs to be done to understand the function of these genes in the frog brain. Further, the recent identification of gene expression patterns that are associated with extinction in the brain of Bombina orientalis [Lewis et al., 2021] provides an opportunity for us to contrast mechanisms of species differences in learned inhibition in future studies.

\section{Summary, Conclusions, and Future Directions}

In summary, we have contrasted two species of frog that differ in spatial and social ecology and found that they differ in hippocampally dependent cognition. Using RNA sequencing, we find that these differences in cogni- tion are reflected by differences in expression of genes in the medial pallium that are associated with neurogenesis, apoptosis, synaptic plasticity, and regulation of cellular activity. Our work is consistent with results from other vertebrates that show that ecology shapes cognition by acting on the hippocampus.

The picture that has emerged from our work linking ecology, cognition, and the hippocampus in our species contrast is illuminating, but incomplete. For example, whether the species differences in cognition we have discovered are limited to visual cues is unknown. While spatial learning is almost always investigated in the context of visual cues, other modalities, including audition and olfaction, are suitable for spatial navigation and may be more salient to túngara frogs. We feel, therefore, that an important extension of our work would be to investigate the extent to which cognitive abilities are modality dependent. In addition, it will be important for future studies to establish the function of the medial pallium of our species in spatial learning and learned inhibition. Our assumption, so far, that these aspects of cognition are hippocampally dependent are based on inferences from other species (primarily amniotes), but, given that we are ultimately interested in understanding how ecology has shaped cognition through the hippocampus, functional studies in our focal species are an important next step. Similarly, our gene expression studies are limited by several factors, including sample sizes and the necessary dependence on a distant relative (Xenopus) for assigning transcripts to genes. Nonetheless, our initial studies suggest that a methodical investigation of genomic differences between túngara and D. auratus is likely to be fruitful. Combined with in-depth physiological investigation of the similarities and difference of the medial pallium of the túngara frog and D. auratus, this work will contribute to our ability to connect cognitive phenotype to underlying genetic and neural mechanisms.

The hippocampus is one of the best studied brain regions in vertebrates. However, we still struggle to understand how the evolution of its structure relates to the evolution of its function [Day, 2003; Salas et al., 2003; Striedter, 2016; Butler, 2017]. Ultimately, though, if we are interested in the evolution of the vertebrate hippocampus, work on amphibians is not just needed, it is imperative. We believe that contrasting the structure-function relationships of the hippocampus in amphibians can yield insight into the evolutionary history of the vertebrate hippocampus that is not possible by working in other groups. 


\section{Acknowledgements}

There is no way I could ever express in words my profound gratitude to Walter Wilczynski and the role he played in my intellectual development. Not only was I introduced to the fascinating field of comparative cognition, but I also learned by example the reward of pursuing questions driven by my curiosity. Lainy Day was an essential collaborator on the initial stages of this project and I'm deeply grateful for her patience as I learned to "navigate" the rather dense cognition literature that was mostly new to me. Yuxiang Liu was the graduate student who made this all happen. Looking back, I can see that suggesting he consider pioneering a new research direction in my lab may not have been entirely prudent. But his singular combination of talents enabled him to rise to the challenge. Finally, like any research, there are innumerable others who contributed in various ways to the research I described here, including Cody Sorrell, Robert Ventura, and Jo-Hsien (Anita) Yu.

\section{Statement of Ethics}

The research described here complies with internationally accepted standards for research and reporting, including animal research that was approved by the University of North Carolina's Institutional Animal Care and Use Committee (protocol 19-285).

\section{Conflict of Interest Statement}

The author has no conflicts of interest to declare.

\section{Funding Sources}

This research was not funded.

\section{Author Contributions}

Sabrina Burmeister is solely responsible for the content of this article.

\section{Data Availability Statement}

Data will be made available upon request.

\section{References}

Abisambra JF, Fiorelli T, Padmanabhan J, Neame P, Wefes I, Potter H. LDLR expression and localization are altered in mouse and human cell culture models of Alzheimer's disease. PLoS One. 2010;5(1):e8556.

Amici F, Aureli F, Call J. Fission-fusion dynamics, behavioral flexibility, and inhibitory control in primates. Curr Biol. 2008;18(18):1415-9.

Banquet JP, Gaussier P, Cuperlier N, Hok V, Save E, Poucet B, et al. Time as the fourth dimension in the hippocampus. Prog Neurobiol. 2021;199:101920.

Bilbo SD, Day LB, Wilczynski W. Anticholinergic effects in frogs in a Morris water maze analog. Physiol Behav. 2000;69:351-7.

Bingman VP, Erichsen JT, Anderson JD, Good MA, Pearce JM. Spared feature-structure discrimination but diminished salience of environmental geometry in hippocampal lesioned homing pigeons (Columba livia). Behav Neurosci. 2006;120:835-41.

Bingman VP, Muzio RN. Reflections on the structural-functional evolution of the hippocampus: what is the big deal about a dentate gyrus? Brain Behav Evol. 2017;90:53-61.

Bond AB, Kamil AC, Balda RP. Serial reversal learning and the evolution of behavioral flexibility in three species of North American corvids (Gymnorhinus cyanocephalus, Nucifraga columbiana, Aphelocoma californica). J Comp Psychol. 2007;121(4):37279.

Branch CL, Semenov GA, Wagner DN, Sonnenberg BR, Pitera AM, Bridge ES, et al. The ge- netic basis of spatial cognitive variation in a food-caching bird. Curr Biol. 2021;32:1-10.

Brasted PJ, Bussey TJ, Murray EA, Wise SP. Role of the hippocampal system in associative learning beyond the spatial domain. Brain. 2003;126:1202-23.

Brodbeck DR. Memory for spatial and local cues: a comparison of a storing and a nonstoring species. Anim Learn Behav. 1994;22(2):11933.

Brodbeck DR, Shettleworth SJ. Matching location and color of a compound stimulus: comparison of a food-storing and non-storing bird species. J Exp Psychol Anim Behav Proc. 1995;21:64-77.

Brown JL, Morales V, Summers K. A key ecological trait drove the evolution of biparental care and monogamy in an amphibian. Am Nat. 2010 Apr;175(4):436-46.

Burmeister SS, Rodriguez Moncalvo VG, Pfennig KS. Monoaminergic integration of diet and social signals in the brains of juvenile spadefoot toads. J Exp Biol. 2017;220:3135-41.

Burmeister SS, Rodriguez Moncalvo VG, Pfennig KS. Differential encoding of signals and preferences by noradrenaline in the anuran brain. J Exp Biol. 2020;223:jeb214148.

Butler AB. Of horse-caterpillars and homologies: evolution of the hippocampus and its name. Brain Behav Evol. 2017;90(1):7-14.

Butler AB, Hodos W. Comparative vertebrate neuroanatomy: evolution and adaptation. New York: Wiley-Liss; 1996.
Carvajaal-Castro JD, Vargas-Salinas F, CasasCardona S, Rojas B, Santos JC. Aposematism facilitates the diversification of parental care strategies in poison frogs. Sci Rep. 2021;11: 19047.

Chan KH, Morell JR, Jarrard LE, Davidson TL. Reconsideration of the role of the hippocampus in learned inhibition. Behav Brain Res. 2001;119:111-30.

Cheng K. A purely geometric module in the rat's spatial representation. Cognition. 1986;23(2): $149-78$.

Cho CH, Yang Z, Yoo KH, Oliveros A, Jang MH. BubR1 insufficiency impairs affective behavior and memory function in mice. Int Neurourol J. 2018;22:S122.

Chu J, Wilczynski W, Wilcox RE. Pharmacological characterization of the D1- and D2-like dopamine receptors from the brain of the leopard frog, Rana pipiens. Brain Behav Evol. 2001;57(6):328-42.

Clayton NS, Krebs JR. Lateralization and unilateral transfer of spatial memory in marsh tits: are two eyes better than one? J Comp Physiol A. 1994;174(6):769-73.

Das UN. Can memory be improved? A discussion on the role of ras, GABA, acetylcholine, NO, insulin, TNF- $\alpha$, and long-chain polyunsaturated fatty acids in memory formation and consolidation. Brain Devel. 2003;25: 251-61.

Davis HP, Squire LR. Protein synthesis and memory: a review. Psychol Bull. 1984;96:518. 
Day LB. The importance of hippocampus-dependent non-spatial tasks in analyses of homology and homoplasy. Brain Behav Evol. 2003; 62(2):96-107.

Day LB, Crews D, Wilczynski W. Relative medial and dorsal cortex volume in relation to foraging ecology in congeneric lizards. Brain Behav Evol. 1999a Dec;54(6):314-22.

Day LB, Crews D, Wilczynski W. Spatial and reversal learning in congeneric lizards with different foraging strategies. Anim Behav. 1999b;57:393-407.

Dole JW. Homing in leopard frogs, Rana pipiens. Ecology. 1968;49(3):386-99.

Dunbar RI, Shultz S. Evolution in the social brain. Science. 2007 Sep 7;317(5843):1344-7.

Ellins SR, Cramer RE, Martin GC. Discrimination reversal learning in newts. Anim Learn Behav. 1982;10(3):301-4.

Engel DF, Grzyb AN, de Oliveira J, Pötzsch A, Walker TL, Brocardo PS, et al. Impaired adult hippocampal neurogenesis in a mouse model of familial hypercholesterolemia: a role for the LDL receptor and cholesterol metabolism in adult neural precursor cells. Mole Metab. 2019;30:1-15.

Ewert JP, Buxbaum-Conradi H, Dreisvogt F, Glagow M, Merkel-Harff C, Röttgen A, et al. Neural modulation of visuomotor functions underlying prey-catching behaviour in anurans: perception, attention, motor performance, learning. Comp Biochem Physiol A Mol Integr Physiol. 2001;128:417-61.

Garamszegi LZ, Marcel Eens M. The evolution of hippocampus volume and brain size in relation to food hoarding in birds. Ecol Lett. 2004; 7:1216-24.

Godfrey-Smith P. Environmental complexity and the evolution of cognition. In: Sternberg R, Kaufman J, editors. The evolution of intelligence. Mahwah, NJ: Erlbaum; 2002. p. 23349.

Gould KL, Gilbertson KE, Seyfer AL, Brantner RM, Hrvol AJ, Kamil AC, et al. Differences in relative hippocampus volume and number of hippocampus neurons among five corvid species. Brain Behav Evol. 2013;81:56-70.

Healy SD. Adaptation and the brain. Oxford: Oxford University Press; 2021.

Healy SD, Krebs JR. Food storing and the hippocampus in corvids: amount and volume are correlated. Proc R Soc Lond B. 1992;248:24145.

Holtzman DA, Harris TW, Aranguren G, Bostock E. Spatial learning of an escape task by young corn snakes, Elaphe guttata guttata. Anim Behav. 1999;57:51-60.

Hosseinzadeh S, Zahmatkesh M, Heidari M, Hassanzadeh GR, Karimian M, Sarrafnejad A, et al. Hippocampal DHCR24 down regulation in a rat model of streptozotocin-induced cognitive decline. Neurosci Lett. 2015;587:10712.

Jarrard LE. What does the hippocampus really do? Behav Brain Res. 1995;71:1-10.
Koudinov AR, Koudinova NV. Essential role for cholesterol in synaptic plasticity and neuronal degeneration. FASEB J. 2001;15:1858-60.

LaDage LD, Roth TCII, Pravosudov VV. Biases in measuring the brain: the trouble with the telencephalon. Brain Behav Evol. 2009;73(4): 253-8.

Lavenex P, Shiflett MW., Lee RK, Jacobs LF. Spatial versus nonspatial relational learning in free-ranging fox squirrels (Sciurus niger). J Comp Psychol. 1998;112:127-36.

Lewis V, Laberge F, Heyland A. Transcriptomic signature of extinction learning in the brain of the fire-bellied toad, Bombina orientalis. Neurobiol Learn Mem. 2021;184:107502.

Liu Y, Burmeister SS. Sex differences during place learning in the túngara frog. Anim Behav. 2017;128:61-7.

Liu Y, Day LB, Summers K, Burmeister SS. Learning to learn: advanced behavioural flexibility in a poison frog. Anim Behav. 2016;111:16772.

Liu Y, Day LB, Summers K, Burmeister SS. A cognitive map in a poison frog. J Exp Biol. 2019; 222:197467.

Liu Y, Jones CD, Day LB, Summers K, Burmeister SS. Cognitive phenotype and differential gene expression in a hippocampal homologue in two species of frog. Integr Comp Biol. 2020; 60(4):1007-23.

Lopez JC, Broglio C, Rodriguez F, Thinus-Blanc C, Salas C. Multiple spatial learning strategies in goldfish (Carassius auratus). Anim Cog. 1999;2:109-120.

Lopez JC, Rodriguez F, Gomez Y, Vargas JP, Broglio C, Salas C. Place and cue learning in turtles. Anim Learn Behav. 2000;28:360-72.

MacDonald IMV. Field experiments on duration and precision of grey and red squirrel spatial memory. Anim Behav. 1997;54:879-91.

Mackintosh NJ. Do not ask whether they have a cognitive map, but how they find their way about. Psicologica. 2002;23:165-85.

McGregor A, Hayward AJ, Pearce JM, Good MA. Hippocampal lesions disrupt navigation based on the shape of the environment. Behav Neurosci. 2004; 118:1011-21.

Morris RG, Garrud P, Rawlins JN, O’Keefe J. Place navigation impaired in rats with hippocampal lesions. Nature. 1982;297:681-3.

Muzio RN, Segura ET, Papini MR. Effects of lesions in the medial pallium on instrumental learning in the toad (Bufo arenarum). Physiol Behav. 1993 Jul;54(1):185-8.

O'Keefe J, Burgess N. Geometric determinants of the place fields of hippocampal neurons. $\mathrm{Na}$ ture. 1996;381:425-28.

O'Keefe JO, Nadel L. The hippocampus as a cognitive map. New York: Oxford University Press; 1978.

Pravosudov VV, Clayton NS. A test of the adaptive specialization hypothesis: Population differences in caching, memory, and the hippocampus in black-capped chickadees (Poecile atricapilla). Behav Neurosci. 2002 Aug; 116(4):515-22.
Pravosudov VV, de Kort SR. Is the western scrub jay (Aphelocoma californica) really an underdog among food-caching corvids when it comes to hippocampal volume and food caching propensity? Brain Behav Evol. 2006;67: $1-9$.

Pravosudov VV, Roth TCII, Forister ML, LaDage LD, Kramer R, Schilkey F, et al. Differential hippocampal gene expression is associated with climate-related natural variation in memory and the hippocampus in food-caching chickadees. Mole Ecol. 2013;22(2):397408 .

Pravosudov VV, Smulders TV. Integrating ecology, psychology and neurobiology within a food-hoarding paradigm. Philos Trans R Soc Lond B Biol Sci. 2010;365:859-67.

Pröhl H. Territorial behavior in dendrobatid frogs. J Herpetol. 2005;39(3):354-65.

Puddington MM, Daneri MF, Papini MR, Muzio RN. Telencephalic neural activation following passive avoidance learning in a terrestrial toad. Behav Brain Res. 2016;315:75-82.

Roth G, Laberge F, Mühlenbrock-Lenter S, Grunwald $\mathrm{W}$. Organization of the pallium in the fire-bellied toad Bombina orientalis. I: morphology and axonal projection pattern of neurons revealed by intracellular biocytin labeling. J Comp Neurol. 2007;501:443-64.

Roth G, Westhoff G. Cytoarchitecture and connectivity of the amphibian medial pallium. Eur J Morphol. 1999 Apr;37(2-3):166-71.

Ryan MJ. The túngara frog: a study in sexual selection and communication. Chicago: The University of Chicago Press; 1985.

Sakimoto Y, Sakata S. Hippocampal theta activity during behavioral inhibition for conflicting stimuli. Behav Brain Res. 2014;275:183-90.

Salas C, Broglio C, Rodríguez F. Evolution of forebrain and spatial cognition in vertebrates: conservation across diversity. Brain Behav Evol. 2003;62:72-82.

Sherry DF, Hoshooley JS. Seasonal hippocampal plasticity in food-storing birds. Philos Trans R Soc Lond B Biol Sci. 2010;365:933-43.

Sherry DF, Jacobs LF, Gaulin SJ. Spatial memory and adaptive specialization of the hippocampus. Trends Neurosci. 1992;15(8):298-303.

Shettleworth SJ. Cognition, evolution, and behavior. Oxford: Oxford University Press; 2009.

Shettleworth SJ, Hampton RR. Adaptive specializations of spatial cognition in food storing birds? Approaches to testing a comparative hypothesis. In: Pepperberg I, Balda R, Kamil AC, editors. Animal cognition in nature. San Diego, CA: Academic Press; 1998. p. 65-98.

Sotelo MI, Daneri MF, Bingman VP, Muzio RN. Telencephalic neuronal activation associated with spatial memory in the terrestrial toad Rhinella arenarum: participation of the medial pallium during navigation by geometry. Brain Behav Evol. 2016;88:149-60.

Striedter GF. Evolution of the hippocampus in reptiles and birds. J Comp Neurol. 2016;524: 496-517.
Ecology, Cognition, and the

Hippocampus: A Tale of Two Frogs
Brain Behav Evol 2022;97:211-224

DOI: $10.1159 / 000522108$ 
Summers K. Sexual conflict and deception in poison frogs. Curr Zool. 2014;60(1):37-42.

Summers K, Clough ME. The evolution of coloration and toxicity in the poison frog family (Dendrobatidae). Proc Natl Acad Sci U S A. 2001;98(11):6227-32.

Vági B, Végvári Z, Liker A, Freckleton RP, Székely T. Parental care and the evolution of terrestriality in frogs. Proc R Soc B. 2019;286: 20182737.

Ventura RE, Liu Y, Burmeister SS. Reconsidering sex differences during place learning in túngara frogs. Curr Zool. 2019;65(3):317-21.
Vilà-Balló A, Mas-Herrero E, Ripollés P, Simó M, Miró J, Cucurell D, et al. Unraveling the role of the hippocampus in reversal learning. J Neurosci. 2017;37(28):6686-97.

Vorhees CV, Williams MT. Morris water maze: procedures for assessing spatial and related forms of learning and memory. Nat Protoc. 2006; 1:848-58

Wang SH, Huang Y, Yuan Y, Xia WQ, Wang P, Huang R. LDL receptor knock-out mice show impaired spatial cognition with hippocampal vulnerability to apoptosis and deficits in synapses. Lipids Health Dis. 2014;13:175.
Westhoff G, Roth G. Morphology and projection pattern of medial and dorsal pallial neurons in the frog Discoglossus pictus and the salamander Plethodon jordani. J Comp Neurol. 2002;445:97-121.

Yang EJ, Wilczynski W. Relationships between hormones and aggressive behavior in green anole lizards: an analysis using structural equation modeling. Horm Behav. 2002;42(2):192-205.

Yang Z, Jun H, Choi CI, Yoo KH, Cho CH, Hussaini SMQ, et al. Age-related decline in BubR1 impairs adult hippocampal neurogenesis. Aging Cell. 2017;16(3):598-601. 